\title{
Learning Process of the Steel Use in Building Engineering Students
}

\author{
Carolina Cabrera, Carlos Moron*, Alfonso Garcia \\ Sensors and Actuators Group, Dtpo. Tecnología de la Edificación, Escuela Técnica Superior de Edificacion, Universidad Politécnica de \\ Madrid, Spain \\ *Corresponding author: carlos.moron@upm.es
}

Received May 03, 2014; Revised June 04, 2014; Accepted June 04, 2014

\begin{abstract}
The present work has as main aim to make a small introduction about the types of steels, specially the ones used in the construction industry. This material is appreciated in construction due to its many advantages as strengths, resistance, adaptability and flexibility in design, durability, recyclability,...; even thou its also has week points like a low resistance to fire, weak against corrosion and a high initial cost compared with other materials. There are a high variety of ways to classify steel. So, it is very important to the building engineering students to know the classification of steel will be focused on the chemical composition of the steel, as it is the most common way of classifying it. The different types of steel will be grouped in four types: carbon steel, alloy steel, stainless steel and tool steel. In carbon steel the main alloying constituent is carbon, in a range between $0.12 \%$ and $2 \%$. It may also content small amounts of other elements like manganese, sulphur, phosphorus and silicon. Variations in the carbon content of carbon steel can modify its mechanical properties, for example, with an increase in the carbon content from 0.01 to $1.5 \%$ in the alloy, its strength and hardness increases but still such an increase beyond $1.5 \%$ causes appreciable reduction in the ductility and malleability of the steel. Alloy steel is a term used referring to steels with other alloying elements in addition to the carbon. The content of this alloying element is between $1.0 \%$ and $50 \%$ by weight. The most common alloying elements used in this type of steel are manganese, nickel, chromium, molybdenum, vanadium, silicon, and boron; less common alloyants are aluminium, cobalt, copper, cerium, niobium, titanium, tungsten, tin, zinc, lead, and zirconium. By varying the alloy proportions steel properties such as hardenability, corrosion resistance, strength, formability, weldability or ductility can be manipulated. Stainless steel is the alloy of any type of iron that contains at least $10.50 \%$ of chromium and no more than $1.20 \%$ of carbon. It also may content other alloy elements such as nickel or molybdenum. These steels can be divided into four groups based on their crystalline structure. Tool steels is a variety of carbon and alloy steels, its carbon content ranges between $0.7 \%$ and $1.5 \%$, it also contains tungsten, molybdenum, cobalt and vanadium in varying quantities to increase heat resistance and durability. They are ideal for cutting and drilling equipment, this suitability comes from their distinctive hardness, resistance to abrasion, their ability to hold a cutting edge, and/or their resistance to deformation at elevated temperatures (red-hardness).
\end{abstract}

Keywords: Innovation Steel, construction, recycle, re-use, chemical composition

Cite This Article: Carolina Cabrera, Carlos Moron, and Alfonso Garcia, "Learning Process of the Steel Use in Building Engineering Students.” American Journal of Educational Research, vol. 2, no. 6 (2014): 366-371. doi: 10.12691/education-2-6-6.

\section{Introduction}

Steel is a metal material known by the human been since ancient times. It comes from the alloy between iron and carbon, being carbon the primary alloying element, and its content in the steel is between $0.002 \%$ and $2.1 \%$ by weight. Additional elements may also be present in steel as manganese, phosphorus, sulphur, silicon, or aluminium, creating so different types of steel. The possibility of adjusting its composition and internal structure to tailor its properties makes the steel a highly versatile material.

The ancients recognised the value of steel, and also knew the arts of hardening and tempering it. The earliest known production of steel is a piece of ironware excavated from an archaeological site in Anatolia (Kaman-Kalehoyuk) [1] and is about 4,000 years old. This material has evolved since then reaching the building industry during the industrial revolution in the $19^{\text {th }}$ century. The first all-steel frame building was the Rand McNally Building in Chicago (1886). But it was not until the early 20th century during the World War II, when using steel in construction became more widespread and steel became more available.

Now a days, in an era of architectural and engineering innovation, steel plays a main role in many of the most sophisticated and accomplished examples of modern building design. This material has amazed architects as well as engineers due to its outstanding design opportunities. 
Using steel in the construction industry has been widely accepted due to its many advantages like its high strength, resistance, load carrying ability, adaptability and flexibility in design, durability, recyclability, for its relatively low weight, it low construction costs due to the high construction speed or its reduced long term maintenance costs. Another reason why architects and engineers feel attract by steel is that it lends itself to prefabrication, whole structures can be created in a factory environment and then constructed quickly on site. Steel buildings are highly adaptable in that frames can be modified and altered.

Even tough, this material also has some disadvantages like its low resistance to fire, weakness against corrosion especially in marine environments and a high initial cost compared with other materials.

According to the World Steel Association data, in 2012, the total world crude steel produced was 1,547.8 million metric tonnes (mmt). The biggest steel producing country was China, which accounted for $46.3 \%$ of world steel production in 2012, followed by Europe (169.4 mmt), Japan (107.2 mmt) and United States (88.6 mmt).

Most of the steel produced is destined to construction; as it can be seen in Figure 1, it represents approximately $50 \%$ of the global steel consumption being higher in the USA (60\%) and lower in China (40\%). In Figure 1, it can also be appreciated that engineering and/or machinery represents a $20 \%$ of the steel produced, metal goods as well as transport a 10\%, consumer goods and others a $5 \%$.

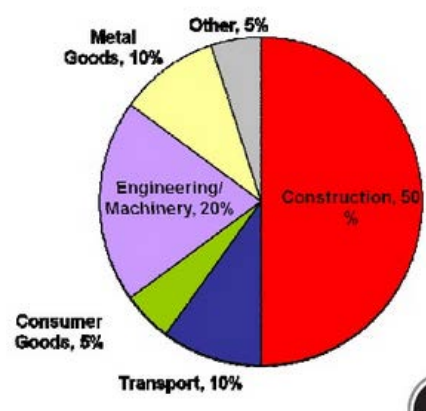

Steel Business Briefing Faster ' Closer - Further

Figure $1 . \quad$ Steel consumption. Sourse: http://www.slideshare.net/SteelBusinessBriefing/steel-construction

\section{Steel Making Process}

Steelmaking is the process through which steel is produced for from iron and ferrous scrap. In steelmaking, alloying elements such as manganese, nickel, chromium and vanadium are added to produce different types of steel, and impurities such as nitrogen, silicon, phosphorus, and excess carbon are removed from the raw iron. It is also important to limit of dissolved gases such as nitrogen and oxygen, and entrained impurities (termed "inclusions") in order to ensure the quality of the products cast from the liquid steel.

There are many steelmaking process methods, like the Bessemer, Siemens Open Hearth, electric high-frequency or crucible processes, but there are two major processes for making steel: basic oxygen and electric arc furnace (EAF) steelmaking [2]. Oxygen steelmaking is fuelled predominantly by the exothermic nature of the reactions inside the vessel where as in EAF steelmaking, electrical energy is used to melt the solid scrap and/or direct reduced iron (DRI) materials. In recent times, EAF steelmaking technology has evolved closer to oxygen steelmaking as more chemical energy is introduced into the process [3].

\subsubsection{Electric Arc Furnace Process}

An Electric Arc Furnace (EAF) is a furnace that heats charged material by means of an electric arc. It uses scrap steel or direct reduced iron (DRI) as the main feed materials, Although steelmaking arc furnaces generally use scrap steel as their primary feedstock, if hot metal from if a blast furnace or direct-reduced iron is available economically, these can also be used as furnace feed. The impure slags are removed by tilting the furnace. A second limey slag is used to remove sulphur and to deoxidise the metal in the furnace. This result in a high degree of purification and high quality steel can be made, so long as gas absorption due to excessively high temperatures is avoided. This process is used extensively for making highly alloyed steel such as stainless, heat-resisting and high-speed steels.

Another advantage of this process, apart from the high quality, is allows steel to be made from a $100 \%$ scrap metal feedstock. This greatly reduces the energy required to make steel when compared with primary steelmaking from ores. Its flexibility is also a benefit, while blast furnaces cannot vary their production by much and can remain in operation for years at a time, EAFs can be rapidly started and stopped, allowing the steel mill to vary production according to demand.

A typical steelmaking arc furnace is the source of steel for a mini-mill, which may make bars or strip product. Mini-mills can be sited relatively near to the markets for steel products, and the transport requirements are less than for an integrated mill, which would commonly be sited near a harbour for access to shipping.

Oxygen lancing is often used for removing carbon in the presence of chromium and enables scrap stainless steel to be used. The nitrogen content of steels made by the Bessemer and electric arc processes is about 0,01-0,25\% compared with about $0,002-0,008 \%$ in open hearth steels.

\subsubsection{Basic Oxygen Process}

Basic oxygen steelmaking (BOS), also known as LinzDonawitz-Verfahren steelmaking or the oxygen converter process [4] is a method of primary steelmaking in which carbon-rich molten pig iron is made into steel. Blowing oxygen through molten pig iron lowers the carbon content of the alloy and changes it into low-carbon steel. The process is known as basic due to the type of refractories calcium oxide and magnesium oxide that line the vessel to withstand the high temperature of the molten metal

The process was developed in 1948 by Robert Durrer and commercialized in 1952-1953 by Austrian VOEST and ÖAMG. Basic oxygen steelmaking processes is a refined version of the Bessemer converter where blowing of air is replaced with blowing oxygen. It reduces capital costs of plants, time of smelting, and increases so the labour productivity. Between 1920 and 2000, labour requirements in the industry decreased from more than 3 worker-hours per tonne to just 0.003 . The vast majority of steel manufactured in the world is produced using the basic oxygen furnace; in 2000, it accounted for $60 \%$ of 
global steel output [5]. Modern furnaces will take a charge of iron of up to 350 tons and convert it into steel in less than 40 minutes, compared to 10-12 hours in an open hearth furnace [5].

\subsubsection{Crucible and High-Frequency Method}

In high frequency induction furnace, the heat is generated in the metal itself through currents induced by a magnetic field set up by an alternating current, which surrounding the crucible it passes round water-cooled coils. With the square of the frequency the currents increase, being necessary an input current which alternates from 500 to 2000 hertz. As the frequency increases, the currents tend to travel nearer and nearer the surface of a charge. The heat developed in the charge depends on the cross-sectional area which carries current, and large furnaces use frequencies low enough to get adequate current penetration.

Uniformity of the analysis is promoted by the automatic circulation of the melt in a vertical direction, caused by currents. These electric furnaces are being used to produce high quality steels, such as ball bearing, stainless, magnet, die and tool steels.

\subsubsection{Acid and Basic Steel Method}

This method for making steel is focus on removing impurities from pig iron or a mixture of pig iron and steel scrap. The way of removing the impurities depends on whether the slag used in an acid (siliceous) or basic (limey). An acid slag requires the use of an acid furnace lining (silica); and a basic slag demands a basic lining of magnesite or dolomite, with line in the charge. With an acid slag silicon, manganese and carbon only are removed by oxidation, consequently the raw material must not contain phosphorus and sulphur in amounts exceeding those tolerable in the finished steel.

In the basic processes, silicon, manganese, carbon, phosphorus and sulphur can be removed from the charge; commonly the raw material contains low silicon and high phosphorus contents. To remove the phosphorus the bath of metal used must be oxidised to a greater extent than in the corresponding acid process, so the final quality of the steel depends very mostly on the degree of this oxidation.

In the acid processes, deoxidation can take place in the furnaces, a reasonable time is left for the inclusions to rise into the slag and so be removed before casting. On the other hand in the basic furnaces, deoxidation is rarely carried out in the presence of the slag, because phosphorus would return to the metal. Deoxidation of the metal frequently takes place in the ladle, leaving only a short time for the deoxidation products to be removed. For these reasons acid steel is considered better than basic for certain purposes, such as large forging ingots and ball bearing steel

\subsubsection{Bessemer Steel Method}

There are two Bessemer processes, Acid Bessemer and Basic Bessemer (or Thomas), in both processes a molten pig iron is refined by blowing air through it in an eggshaped vessel, known as a converter, of 15-25 tonnes capacity. The oxidation of the impurities raises the charge to a suitable temperature; which is therefore dependent on the composition of the raw material for its heat: $2 \%$ silicon in the acid and 1,5-2\% phosphorus in the basic process is normally necessary to supply the heat. The "blowing" of the charge, which causes an intense flame at the mouth of the converter, this short interval of around 25 minutes, complicates the exact control of the process.

The Acid Bessemer suffered a decline in favour of the Acid Open Hearth steel process, mainly due to economic factors which in turn has been ousted by the basic electric arc furnace.

The Basic Bessemer process is widely more used than the Acid Bessemer method, due to its capacity for making, from a very suitable pig iron, a cheap class of steel, ship plates, or structural sections. For making steel castings a modification known as a Tropenas converter is used, in which the air impinges on the surface of the metal from the sides instead of from the bottom. The raw material is usually melted in a cupola and weighed then the amounts are charged into the converter.

\subsubsection{Open-Hearth Process}

The Basic Open Hearth process also called Siemensmartin Process, steelmaking technique that for most of the 20th century accounted for the major part of all steel made in the world. This process consists on burning excess of carbon and other impurities out of pig iron to produce steel.

The first step of this process is to inspect for possible damage and repair if needed, the furnace. After this, the furnace is charged with light scrap, such as sheet metal, shredded vehicles or waste metal. Once it has melted, heavy scrap, such as building, construction or steel milling scrap is added, together with pig iron from blast furnaces. Once all steel has melted, slag forming agents, such as limestone, are added. The oxygen in iron oxide and other impurities decarburize the pig iron by burning the carbon away, forming steel. To increase the oxygen contents of the heat, iron ore can be added to the heat.

This process is far slower than the Bessemer one, and thus easier to control and take samples for quality control. Preparing a heat usually takes $8 \mathrm{~h}$ to $8 \mathrm{~h} 30 \mathrm{~min}$ to complete into steel. As the process is slow, it is not necessary to burn all the carbon away as in Bessemer process, but the process can be terminated at given point when desired carbon contents has been achieved.

The Basic Open Hearth process was used for the bulk of the cheaper grades of steel, but there is a growing tendency to replace this process by large arc furnaces using a single slag process especially for melting scrap.

\section{Steel Types}

Steel can be classified according to many different systems, depending on: chemical composition, manufacturing methods (open hearth, basic oxygen process, electric furnace methods,...), finishing methods (hot rolling, cold rolling,...), product form (plate, sheet, strip, tubing, structural shape,...), deoxidation practice (killed, sime-killed and rimmed steel), microstructure (ferritic, pearlitic, martensitic,...), strength level (high or low tensile strength steel) or heat treatment (annealing, quenching, tempering steel,...). 
The most common way to classify steel is through its chemical composition. According to its chemical composition, steel can be classified as:

\subsection{Carbon Steel}

In this type of steel the main alloying constituent is carbon, in a range between $0.12 \%$ and $2 \%$. It may also content small amounts of other elements like manganese, sulphur, phosphorus and silicon. Variations in the carbon content of carbon steel can modify its mechanical properties, for example, with an increase in the carbon content from 0.01 to $1.5 \%$ in the alloy, its strength and hardness increases but if the carbon content is increased beyond $1.5 \%$ it causes an appreciable reduction in the ductility and malleability of the steel.

Carbon steels can be further categorized into three groups depending on their carbon content:

\subsubsection{Low Carbon Steels/Mild Steels}

It contains up to $0,25 \%$ of carbon. Heat treatments improve its ductility, but have no effect in respect of its strength properties.

\subsubsection{Medium Carbon Steels}

It carbon content ranges from 0.25 to $0.70 \%$. By heat treatment it machinability can improve. It must also be highlighted that this steel is especially used for machining or forging and where surface hardness is desirable. The main uses of low- or medium-carbon steel are for sheeting and structural forms because of its amenability to welding and tooling.

\subsubsection{High Carbon Steels}

It contains carbon in the range of 0.70 to $1.05 \%$. In the fully heat-treated condition it is very hard and it will withstand high shear and wear and will thus be subjected to little deformation. High-carbon steel is especially used for dies and cutting tools because of its great hardness and brittleness.

\subsection{Alloy Steel}

Alloy steel is a term used referring to steels with other alloying elements in addition to the carbon. The content of this alloying element is between $1.0 \%$ and $50 \%$ by weight. The most common alloying elements used in this type of steel are manganese, nickel, chromium, molybdenum, vanadium, silicon, and boron; Less common alloyants are aluminium, cobalt, copper, cerium, niobium, titanium, tungsten, tin, zinc, lead, and zirconium. By varying the alloy proportions steel properties such as harden ability, corrosion resistance, strength, formability, weldability or ductility can be manipulated

There are two groups of alloy steel: low-alloy steels and high-alloy steels. The difference between the two is somewhat arbitrary: the UNE EN 10020:2001 norm defines the difference at $<5 \%$ of alloy element in lowalloyed steels and $>5 \%$ of alloy element in high-alloy steel [6], Smith and Hashemi [7] define the difference at $4.0 \%$, while Degarmo [8] define it at 8.0\%.

Applications for alloys steel include pipelines, construction equipment, auto parts, transformers, power generators and electric motors.

\subsection{Stainless Steel}

Stainless steel is the alloy of any type of iron that contains at least $10.50 \%$ of chromium and no more than $1.20 \%$ of carbon. It also may content other alloy elements such as nickel or molybdenum. These steels can be divided into four groups based on their crystalline structure:

\subsubsection{Martensitic}

It contains $11-17 \%$ chromium, less than $0.4 \%$ nickel and up to $1.2 \%$ carbon. These magnetic and heat-treatable steels are used in knives, cutting tools, as well as dental and surgical equipment; it is not commonly used in construction.

\subsubsection{Ferritic}

Ferritic steels contain trace amounts of nickel, 12-17\% chromium, less than $0.1 \%$ carbon, along with other alloying elements, such as molybdenum, aluminium or titanium. These magnetic steels cannot be hardened with heat treatment, but can be strengthened by cold works. This type of steel is often used for urban furniture and architectural decoration.

\subsubsection{Austenitic}

These steels are non-magnetic and non heat-treatable, and generally contain $18 \%$ chromium, $8 \%$ nickel and less than $0.8 \%$ carbon. Austenitic steels form the largest portion of the global stainless steel market and are often used in food processing equipment, kitchen utensils and piping. They are not very used in construction

\subsubsection{Duplex}

These types of stainless steel are chromium-nickelmolybdenum alloys; they are made of two microstructural phases: ferritic and austenitic, reason why they are also known as austenferritic steels. Their chromium content ranges between $18 \%$ and $26 \%$, and its nickel one between $4.5 \%$ and $6.5 \%$. Duplex is specially used in construction exposed to marine environment.

The general properties of stainless steel are summarized in Table 1:

\begin{tabular}{|c|c|c|c|c|c|}
\hline Type & $\begin{array}{l}\text { Corrosion } \\
\text { resistance }\end{array}$ & Hardness & Magnetism & $\begin{array}{c}\text { Hardenable } \\
\text { with } \\
\text { thermal } \\
\text { treatments }\end{array}$ & Weldanility \\
\hline Martensitic & Low & High & Yes & Yes & Poor \\
\hline Ferritic & Good & $\begin{array}{l}\text { Medium- } \\
\text { low }\end{array}$ & Yes & No & Limited \\
\hline Austenitic & Excellent & High & No & No & Excellent \\
\hline Duplex & Excellent & High & Yes & No & Good \\
\hline
\end{tabular}

\subsection{Tool Steel}

Tool steels is a variety of carbon and alloy steels, its carbon content ranges between $0.7 \%$ and $1.5 \%$, it also contains tungsten, molybdenum, cobalt and vanadium in varying quantities to increase heat resistance and durability. They are ideal for cutting and drilling equipment, this suitability comes from their distinctive 
hardness, resistance to abrasion, their ability to hold a cutting edge, and/or their resistance to deformation at elevated temperatures (red-hardness).

The following table (Table 2) summarise the main properties of the different types of steel, previously exposed:

Table 2. General properties of steel. Source: www.efunda.com

\begin{tabular}{|c|c|c|c|c|}
\hline Properties & $\begin{array}{l}\text { Carbon } \\
\text { Steels }\end{array}$ & $\begin{array}{l}\text { Alloy } \\
\text { Steels }\end{array}$ & $\begin{array}{l}\text { Stainless } \\
\text { Steels }\end{array}$ & $\begin{array}{c}\text { Tool } \\
\text { Steels }\end{array}$ \\
\hline $\begin{array}{c}\text { Density } \\
\left(1000 \mathrm{~kg} / \mathrm{m}^{3}\right)\end{array}$ & 7.85 & 7.85 & $7.75-8.1$ & $\begin{array}{c}7.72- \\
8.0\end{array}$ \\
\hline $\begin{array}{c}\text { Elastic Modulus } \\
(\mathrm{GPa})\end{array}$ & $190-210$ & $190-210$ & $190-210$ & $\begin{array}{l}190- \\
210\end{array}$ \\
\hline Poisson's Ratio & $0.27-0.3$ & $0.27-0.3$ & $0.27-0.3$ & $\begin{array}{c}0.27- \\
0.3\end{array}$ \\
\hline $\begin{array}{c}\text { Thermal Expansion } \\
\left(10^{-6} / \mathrm{K}\right)\end{array}$ & $11-16.6$ & $9.0-15$ & $9.0-20.7$ & 9.4-15.1 \\
\hline Melting Point $\left({ }^{\circ} \mathrm{C}\right)$ & & & $1371-1454$ & \\
\hline $\begin{array}{c}\text { Thermal } \\
\text { Conductivity (W/m- } \\
\text { K) }\end{array}$ & $24.3-65.2$ & $26-48.6$ & $11.2-36.7$ & $\begin{array}{l}19.9- \\
48.3\end{array}$ \\
\hline Specific Heat (J/kg-k) & $450-2081$ & $452-1499$ & $420-500$ & \\
\hline $\begin{array}{c}\text { Electrical Resistivity } \\
\left(10^{-9} \mathrm{~W}-\mathrm{m}\right)\end{array}$ & $130-1250$ & $210-1251$ & 75.7-1020 & \\
\hline $\begin{array}{c}\text { Tensile Strength } \\
(\mathrm{MPa})\end{array}$ & $276-1882$ & $758-1882$ & $515-827$ & $\begin{array}{l}640- \\
2000 \\
\end{array}$ \\
\hline Yield Strength (MPa) & $186-758$ & $366-1793$ & $207-552$ & $380-440$ \\
\hline $\begin{array}{c}\text { Percent Elongation } \\
(\%)\end{array}$ & $10-32$ & $4-31$ & $12-40$ & $5-25$ \\
\hline $\begin{array}{c}\text { Hardness (Brinell } \\
\text { 3000kg) }\end{array}$ & 86-388 & $149-627$ & 137-595 & $210-620$ \\
\hline
\end{tabular}

\section{Steel as a Green Material}

Steel is one of the most recycled materials all over the world; moreover steel is more recycled than paper, aluminum, glass or plastic. From the 700 million tonnes/year of global steel production, almost half of it is recycled from scrap [9].

The steel product cycle has five main steps. Firstly recollecting scrap, infrastructure of scrap processors has been in existence for over 100 years. Secondly smelting the steel, Coatings on steel products do not represent a barrier to recycling. The next step is manufacturing, a lot of steel is recycled every however it is not sufficient to meet demand and so over $50 \%$ of steel must be made from primary ore. After manufacturing, the steel is used for its purpose. Finally, the steel is reused at the end of their useful lives.

Steel has long ago been recycled, as it is an unique material in that it always contains recycled content; it is completely recyclable at the end of its product life and may be recycled an unlimited number of times without loss of quality.

The only limitation for recycling steel is its recycling yield, or the percentage which survives from one recycling stage to the next. Several factors determine the recycling yield of this material, like The effectiveness of the recovery process form previous uses, The effectiveness of the collection and sorting system which in steel is facilitated by its magnetic properties and.

The steel scrap industry is well established locally, nationally and internationally and The technical difficulties of reprocessing if the reprocessing is wasteful, the recycling yield will be low.

Currently when speaking of steel as a green material, it is not only seen as a recyclable product but also as a reusual one. Steel buildings can be designed to facilitate disassembly or deconstruction at the end of their useful lives.

An environmental advantage of reusing steel over recycling it, is that steel components recovered in this way reduces the energy, $\mathrm{CO} 2$ and other environmental burdens generally associated with the manufacture of all construction materials. Furthermore, designing for disassembly and re-use reduces neighbourhood disruption and pollution during the demolition process. The percentage of waste going to landfill is also reduced.

\section{Conclusions}

Steel is a greatly appreciated material by architects and engineers due to it many advantages as strengths, resistance, adaptability and flexibility in design, durability, recyclability,...; but it has also some disadvantages so as a low resistance to fire, corrosion problems and a high initial price, due to this it is usually combined with other materials in the construction industry.

The sector with higher global steel consumption is the construction sector, which represents around a $50 \%$ of it. This percentage races a bit in the USA (60\%) and lowers a little in China (40\%).

There are many steelmaking process methods, like the Bessemer, Siemens Open Hearth, electric high-frequency or crucible processes, but the most used steelmaking process methods nowadays are: basic oxygen and electric arc furnace (EAF) steelmaking. The first process is also known as Linz-Donawitz-Verfahren steelmaking or oxygen converter process, it is a method of primary steelmaking in which carbon-rich molten pig iron is made into steel. The second steelmaking process is a furnace that heats charged material by means of an electric arc, it uses scrap steel or direct reduced iron as main feed materials.

There is a great variety of ways to classify steel; the most common way of classifying it is through chemical composition, which groups the steel in to four different types: carbon steel, alloy steel, stainless steel and tool steel. Carbon steel has as main alloying constituent carbon $(0.12 \%-2 \%)$, alloy steel refers to steels with other alloying elements in addition to the carbon, stainless steel is the alloy of any type of iron that contains at least $10.50 \%$ of chromium and no more than $1.20 \%$ of carbon and tool steel which is a variety of carbon and alloy steels (carbon content ranges between $0.7 \%$ and $1.5 \%$ )

The most common type of steel used in construction is carbon steel, because of its suitable mechanical and physical properties for constructions. Even tough the ideal type of steel known till the moment for construction would be stainless steel, especially for marine environments due to its high corrosion resistance. The main reason carbon steel is widely more used in construction than stainless steel is that the second one is much more expensive due to the use of chromium. This problem aggravates as stainless steel is much more sensitive to market fluctuations. 


\section{References}

[1] The Hindu (Chennai, India). 2009-03-26. Ironware piece unearthed from Turkey found to be oldest steel. Retrieved 200903-27.

[2] B. Deo and R. Boom, Fundamentals of Steelmaking Metallurgy, Prentice and Hall, 1993.

[3] E.T. Turkdoagn, Fundamentals of Steelmaking, IOM, 1996.

[4] Brock, James W.; Elzinga, Kenneth G. (1991). Antitrust, the market, and the state: the contributions of Walter Adams. M. E. Sharpe. ISBN 0-87332-855-8 p. 50.

[5] Smil, Vaclav (2006). Transforming the twentieth century: technical innovations and their consequences, Volume 2. Oxford University Press US. ISBN 0-19-516875-5. p99

[6] DEFINITION AND CLASSIFICATION OF GRADES OF STEEL. UNE-EN 10020:2001.

[7] Smith, William F.; Hashemi, Javad (2001), Foundations of Material Science and Engineering (4th ed.), McGraw-Hill, p. 394, ISBN 0-07-295358-6

[8] Degarmo, E. Paul; Black, J T.; Kohser, Ronald A. (2007), Materials and Processes in Manufacturing (10th ed.), Wiley, ISBN 978-0-470-05512-0.

[9] Corus Construction Centre. Recycling and re-used in Steel. Corus Constructuin Centre JD:1000:UK:11/2001.

[10] Street, Arthur \& Alexander, W.O. 1944. Metals in the Service of Man. 11th Edition (1998).
[11] N.R. Badoo. Stainless steel in construction: A review of research, applications, challenges and opportunities. Elsevier july 2008, Journal of Gonstructional Steel Research (2008).

[12] McGannon, Harold E. editor (1971). The Making, Shaping and Treating of Steel: Ninth Edition. Pittsburgh, Pennsylvania: United States Steel Corporation.

[13] J.A.T. Jones, B. Bowman, P.A. Lefrank, "Electric Furnace Steelmaking", in The Making, Shaping and Treating of Steel, R.J. Fruehan, Editor. 1998, The AISE Steel Foundation: Pittsburgh. p. 525-660.

[14] Commerford Martin, Thomas and Leidy Coles, Stepehen; The Story of Electricity, New York 1919, no ISN, Chapter 13 "The Electric Furnace”.

[15] Tweraser, Kurt (2000). The Marshall Plan and the Reconstruction of the Austrian Steel Industry 1945-1953. In: Bischof,Gunther et al. (2000). The Marshall Plan in Austria. Transaction Publishers. ISBN 0-7658-0679-7. pp. 290-322.

[16] AISE, The Marking, Shaping and Treating of Steel-Steelmaking and Refining Volume, The AISE Steel Foundation, 0-930767-02-0.

[17] Béranger, G\& Henry, G, The Book of Steel, Lavoiser Pub, 2-74300022-8.

[18] http://metals.about.com/od/properties/a/Steel-Types-AndProperties.htm(last view 25/11/2013)

[19] www.efunda.com(last view 24/11/2013)

[20] http://www.keytometals.com/Articles/Art2.htm (12/01/2014)

[21] http://www.worldsteel.org/(13/01/2014) 